\title{
Using Model Predictive Control to Modulate the Humidity in a Broiler House and Effect on Energy Consumption
}

\author{
By Norman Urs Baier* \& Thomas Meier ${ }^{ \pm}$
}

In moderate climate, broiler chicken houses are important heating energy consumers and hence heating fuel consumption accounts for a large part in operating costs. They can be reduced by constructional measures, which in turn lead to important costs as well. On the other hand, a software solution to reduce energy would lead to considerably less follow-up costs. The main objective of our work was to assess if it is possible to save energy with a software solution and eventually quantify the savings for a given broiler house in the Swiss Plateau. The investigation was carried out in simulation: the particular broiler house was measured, and a dynamical model for it was derived and validated. To actually search for a particular behaviour of the software that would lead to energy savings, model predictive control was used. The idea was not to specify a particular behaviour of the software but rather to let the software itself find the best behaviour in an exhaustive search. The simulations showed that energy savings can be realised mainly by letting the indoor humidity deviate from what usually is used as setpoint and hence take profit of the outdoor climate, which changes naturally during a 24-hour course. We used expert opinions to determine how long and large these setpoint deviations may be without harming the broilers. The simulations showed also that the light control and the biological activity of the animals reduced the potential savings.

Keywords: Energy conservation, heating, ventilation, and air conditioning (HVAC), implicit model predictive control (MPC), poultry house model, temperature control

\section{Introduction}

In Europe's temperate zone breeding of broilers is usually done in closed poultry houses. Equipped with climate control such houses make it possible to provide for optimal conditions for meat production. Indications on how to regulate the climate within the poultry house are usually given by the supplier of the chicks. In our case we considered ROSS 308 broilers and the corresponding handbook (Aviagen Technical Team 2014). Generally, the required temperature and the recommended humidity vary with the age of the birds. From an economic point of view, it is very important to keep the indoor temperature for the birds within the "thermoneutral zone", a temperature drop below the thermoneutral zone increases the food consumption of the birds without an increase in meat production. On the

*Professor, Bern University of Applied Sciences, Switzerland.

${ }^{ \pm}$Scientific Collaborator, Bern University of Applied Sciences, Switzerland. 
other hand, an excess over the thermoneutral zone will provoke fuel wastage and increased indoor humidity (Donkoh 1989). An excess of indoor humidity can lead to infections and should also be avoided.

The most widespread used control strategy we encountered currently in use was single loop PID- and hysteresis controllers for temperature and humidity control. Usually, the recommended values of the supplier are chosen as setpoints for both control loops, in which the setpoint would be only slowly varying according to the recommendations of the supplier.

In contrast, another control algorithm could be considered, which allows for deviations of the measured temperature and humidity from the recommendations of the chick supplier. We started from the persuasion that the birds will not suffer from stress, when they experience a cold blast, if only it is short enough and as long as the mean temperature lies within the thermoneutral zone. Correspondingly we started from the persuasion that a short raise in humidity will not provoke infections or excessive production of ammonia, if only it is short enough and as long as the mean humidity is unchanged.

Additionally, we started from the hypothesis that during the course of the day, there are times when it is cheaper to ventilate and times where it is more expensive. This hypothesis is supported by the observation that during night times temperatures are often lower than during day times and the cost for heating up a previously completely ventilated room is consequently higher.

With our research we wanted to answer the following questions:

- How can short term deviations from the set-point be implemented in a control algorithm?

- How much energy can be economised using such a control algorithm?

In quest of an answer to the first question, our choice fell on implicit model predictive control (MPC). It naturally allows to formulate a cost function, specifying how expensive fuel is compared to stress or illness.

This article is structured as follows. In the next section "Literature Review" we describe how this work relates to other research works already published. In the section "Methodology" we first describe course of action to answer the research questions raised above. In its subsections we state the physical conditions we considered for our work, furthermore we describe the dynamical model, the cost function and the optimisation algorithm, which altogether form the MPC algorithm. In the section "Results" we show the birds' emission estimated with the dynamical model and used in our simulations. But mainly we use this section to analyse the performance of the MPC. In the section "Discussion" we analyse the plausibility of our results and give a theoretical limit for how large the energy savings due to MPC can be. We finish with "Conclusions". 


\section{Literature Review}

Daskalov et al. (2006) proposed an adaptive non-linear proportional integral control law for broiler houses to reduce coupling and consequently improve disturbance rejection. Lahlouh et al. (2020), on the other hand, analysed the performance of state-PID feedback controllers in presence of disturbances and Mirzaee-Ghaleh et al. (2015) investigated the performance of a fuzzy control algorithm, which also constitutes a MIMO approach to climate regulation. They compared the fuzzy controller to the widespread installed on/off controllers. In their work outside temperature and humidity were both low compared to the requirements of the birds, due to the fact that the broiler house, they modelled, was located in Iran and winter season conditions were considered. Ridolfi de Carvalho Curi et al. (2017) were concerned by the positioning of the sensors to achieve a good performance of the ventilation system.

A distinctively comprehensive approach to modelling and control was taken by Lorencana et al. (2019), who modelled the broiler house as a discrete event system and used finite state machines to model the components of the discrete event system. The work of Stables and Taylor (2006) does not consider the whole building but concentrates on the control of the ventilation rate. The aim is in line with the other cited articles here, namely, to improve set-point tracking and disturbance rejection of the control system. Youssef et al. (2015) propose an alternative controlled variable: Instead of measuring and controlling the indoor temperature, they track the bird's activity as an indication whether or not the birds are in the thermoneutral zone.

Research concentrating on the modelling part has been done by Wicaksono et al. (2017). They introduced an artificial neural network to calculate an "effective temperature", which takes into consideration the humidity and the air flow, thereby allowing the temperature measured near the ground to deviate from the value recommended by the chick supplier. Artificial neural networks have also been used by Abreu et al. (2020) to predict the cloacal temperature of broilers. A model based on the hourly model of ISO 13790 has been presented by Costantino et al. (2018), it is used to estimate the energy consumption for climate control in broiler houses. Due to its coarse time resolution it cannot be used for control, however.

The use of MPC algorithms for doing control of heating, ventilation and air conditioning (HVAC) systems in buildings for human beings has been successfully studied by Zhang et al. (2013). They show graphs with for different control strategies relating "HVAC input cost" to "room temperature violation". Nagpal et al. (2019) relax the necessity for precise weather forecasts by only considering bounds for them.

\section{Methodology}

To give an answer to the question, how varying setpoints can be implemented in a broiler house climate regulation, we implemented an MPC-algorithm. To be able to give a number on how well it performs, we implemented it for a particular 
broiler house currently in use. Sensors were added in such a way that a dynamical model of the broiler house could be developed and validated. Parallel to the modelling, an implicit model predictive control algorithm was developed and the behaviour of the already installed commercial controller was implemented in a simulation model as well. Finally, the measurements of a particular day of one fattening period was used to run the model predictive control on and was compared to the simulation results of the replicated commercial control algorithm. By using the simulation results of the commercial control algorithm and not the true measurement values any effect of disturbances on the result could be eliminated.

In summary, the steps towards the energy comparison between MPC and commercial controller were:

1. Equip a physical broiler house with sensor to be able to calculate the precise heat and humidity balance.

2. Set up a dynamical model describing heat and humidity evolution in the broiler house.

3. With the measured heat and humidity balances and the dynamical model, estimate the animal emissions.

4. Parameterize an MPC algorithm, such that energy can be economised without endangering animal health.

These steps are detailed in this order in the following subsections, except for the estimation of the animal emissions which is given in the next section "Results" only.

\section{Physical Broiler House and Measurement Equipment}

The broiler house used for measurement was located in the Swiss Plateau at an altitude of $450 \mathrm{~m}$. It was equipped with one gas-heating. The heating was particular in the sense that it did heat the room by blowing the exhaust of the burned gas into the broiler house. During normal operation the heating would switch on and off according to a pulse width modulation scheme with a duty cycle provided by the commercial controller (the controller installed by the supplier of the climate control system). The cycle period was approximately $3 \mathrm{~min}$, the red line in the uppermost plot of Figure 1 shows the on-off way of the heating gas supply during normal operation.

To evacuate the waste air, the broiler house had waste air pipes on the top of the roof with an interior vent installed. During winter season, when ventilation is used to reduce the humidity, the ventilation was also controlled in an on-off way, but with a cycle period of approximately $5 \mathrm{~min}$. In summer season when temperature is controlled through the ventilation the behaviour is different. The blue line in the uppermost plot of shows the piloting on-off signal of the original controller. 
Figure 1. Simulated Temperature and Humidity compared to their Measured Counterparts
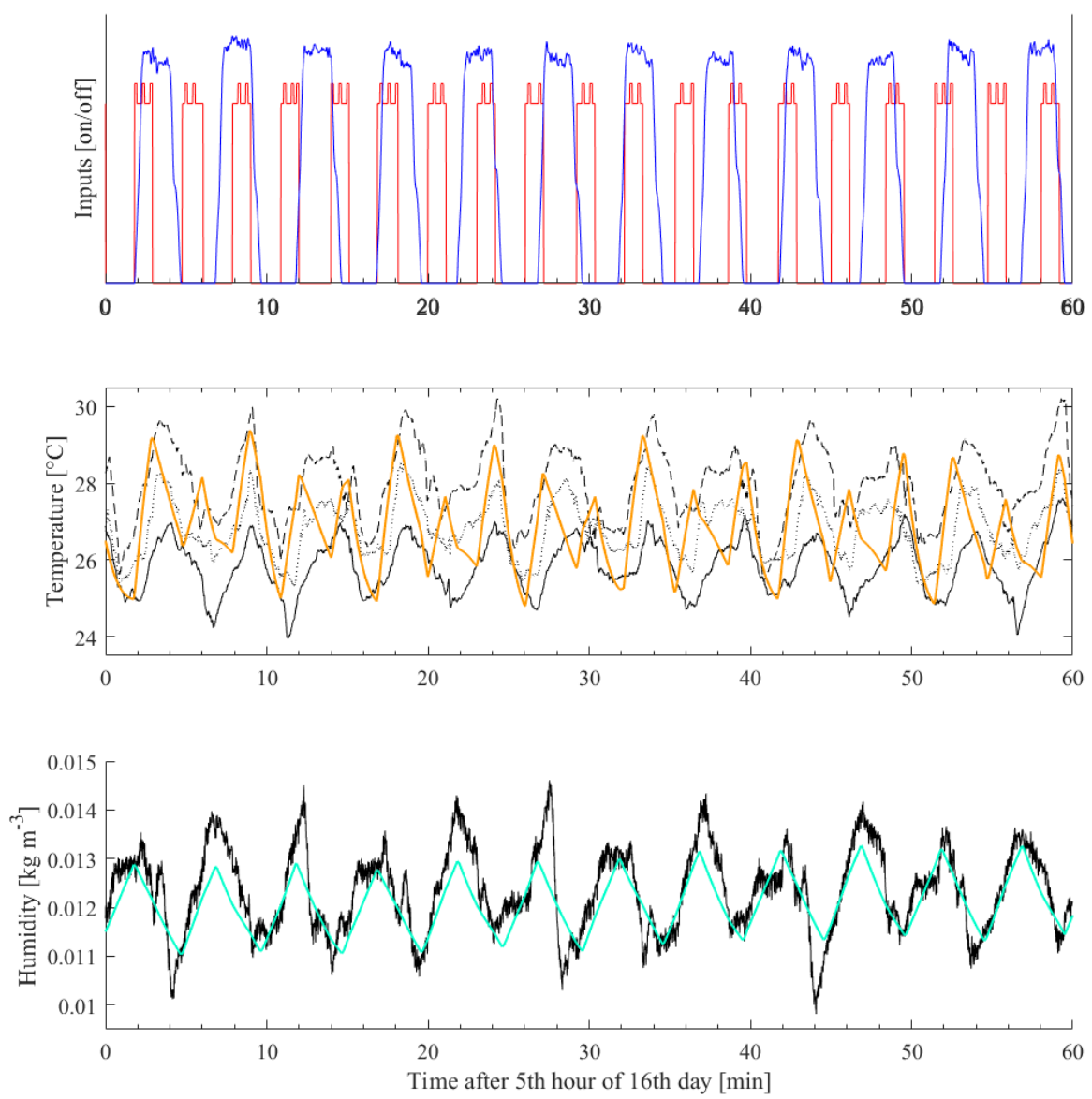

The uppermost plot displays when ventilation (blue) and heating (red) are on. The middle plot shows the measured temperature as black lines (gable, middle, floor) and the amber line shows the simulated temperature for the same hour. The lowermost plot shows the measured humidity in black and the simulated humidity in turquoise.

To be able to measure the heat and humidity balance of the broiler house, an extensive set of sensors was installed in the broiler house next to the sensors already available because of the commercial control system. The sensors installed were one sensor for inside temperature, one for outside temperature, and one each for inside and outside humidity. All original sensors measured one sample every 2 minutes $\left(f_{s} \approx 0.0083 \mathrm{~Hz}\right)$. The original control system recorded signals of water consumption, food consumption, flow rate of the waste air, heating power, setpoint temperature and setpoint humidity $\left(f_{s} \approx 0.0083 \mathrm{~Hz}\right)$.

To be able to better validate the model additional sensors were installed. With the help of two "NI-cRIO"s several other signals were recorded. Inside the broiler house air temperatures at 12 different locations were recorded through thermocouples of type $\mathrm{K}$. The temperature of the floor was measured at two 
different locations with the help of PT100 sensors. Outside air temperature was measured at two different locations. The flow rate of the waste air was also measured through the cRIOs. The cRIOs were set to sample at $1 \mathrm{~Hz}$.

Additionally, a Campbell Scientific data logger was installed to record the following signals: Flow rate in the waste air pipe was measured through a measuring fan $\left(f_{s}=0.5 \mathrm{~Hz}\right)$, temperature of soil outside the broiler house $\left(f_{s} \approx\right.$ $0.0083 \mathrm{~Hz}$ ), and incident solar radiation was measured with a pyranometer $\left(f_{s} \approx 0.0028 \mathrm{~Hz}\right)$. Finally, a weather station was installed recording wind speed, wind direction, (outside) air pressure and humidity with sample intervals of six minutes $\left(f_{s} \approx 0.0028 H z\right)$.

\section{Dynamical Model}

During one step of the MPC-algorithm, the dynamical model is simulated several times. Therefore, for a successful execution of the algorithm a lightweight simulation model is needed. If the model is inaccurate, energy consumption may be estimated inaccurately and may deteriorate the performance of the control algorithm. In this work we compare the behaviour of the installed control algorithm to the MPC when controlling the simulation model presented in this section. Therefore, modelling errors will not lead to a false outperformance of the MPC algorithm but may be an issue when actually using the MPC algorithm in a broiler house.

We start by defining input and output signals of the broiler house from the perspective of the controller. Then we give the equations for the four state variables obtained through heat and humidity balances.

\section{Input and Output Signals of the Broiler House}

The operation mode of the broiler house has been described in the subsection "physical broiler house" already. The broiler house takes the role of the plant within the control system. The controlled variables are the outputs of the plant and correspond to the indoor humidity and the indoor temperature.

The inputs to the system are on one hand: the manipulable inputs ventilation rate $\dot{V}_{v e}(t)$ and heating gas supply/consumption $\dot{V}_{h g}(t)$, on the other hand they are the disturbance inputs: outdoor temperature $T_{\text {ext }}$, outdoor humidity $a_{\text {ext }}$, the heat flows due to the animals $\dot{Q}_{e m}^{+}$and $\dot{W}_{w, e m}^{+}$and the moisture emission of the animals $\dot{m}_{w, e m}$. The subscript "em" designates animal emissions. In the model to be established, the moisture emission is calculated as total water mass given off to the air in the broiler house Figure 2. 
Figure 2. Inputs and Outputs of the "Broiler House"-System: Manipulated Values Left, Disturbance Inputs Top, Outputs Right, State Variables in the Box

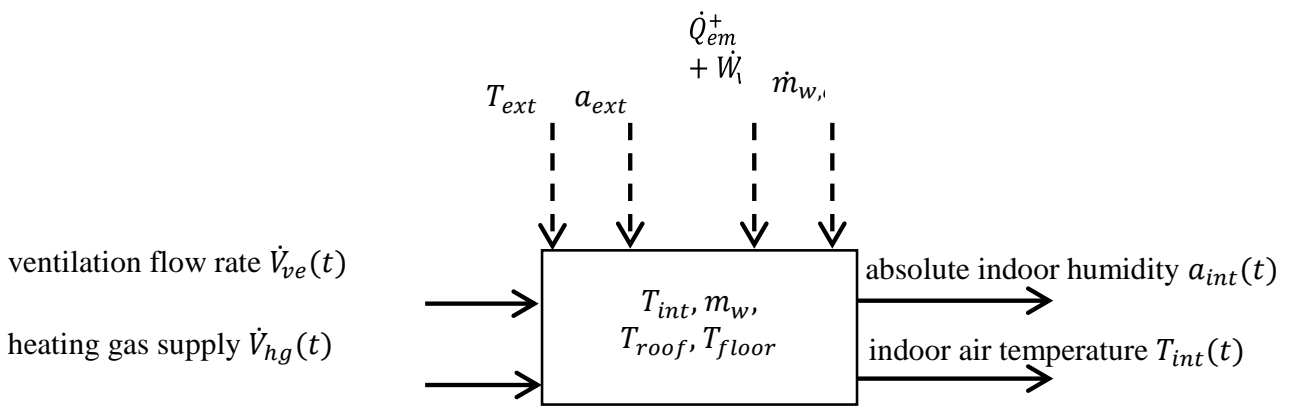

The outdoor temperature and humidity are measured, and forecasts are considered available from weather forecasts. As we worked with simulations, we did use measurements for the forecasts. So, for the scope of this work, we disposed of absolutely reliable forecasts.

The animal emissions are not directly measurable. They are introduced into the broiler house through the food supply. In fact, it is exactly the aim of the climate control to ensure that most of the food supply is assimilated in the birds' bodies by keeping the temperature in the thermoneutral zone. Hence, only a part of the food supply will heat up the broiler house. Extensive work has been done to estimate the efficiency of the breeding and as a side effect, estimates on animal emissions are available (Nukreaw and Bunchasak 2015). However, these estimates are only mean values, whereas it is to expect that the animal emissions vary with time (Pedersen and Sällvik 2002).

The animal emissions leave the broiler house through the ventilation and the walls. Given temperatures and ventilation rates, they could be estimated, but this necessitates a validated model. This appears to be a circular dependency. To escape from it we first built a model from first principles with which we estimated the animal emissions. Then we used the mean values of the emissions known in literature to validate the estimated emissions.

No other disturbances than these measured or modelled disturbances given in this section have been considered. In an actual implementation of the algorithm in a broiler house, disturbances may have an impact on setpoint tracking and performance. How this impact can be minimised and addressed would be part of future research or industrialisation work.

\section{Model from First Principles}

The purpose of the model is to describe the dynamic relation between the above-mentioned input and output signals. The internal temperature can be calculated with the help of thermodynamics and the humidity with the help of the conservation of masses. To apply the corresponding laws, we consider the broiler house as a single mixing volume: When new air is taken into the broiler house, it is immediately mixed with the prevailing air leading to a single temperature and a single humidity in the whole broiler house. The air blown out through the waste air pipes has the temperature and the humidity of the mentioned single mixing 
volume. Measurements of the temperature at different heights in the broiler house are shown in the central plot of Figure 1. They show a slight layering of the air, nevertheless the synchronous variation of the temperature at the different heights indicates an acceptable mixing of the air. Expectedly, some adaptions in the model will have to be done to reflect the layering.

To establish the dynamical model, energy and mass balance equations are used. The approach followed here is similar to the one given by Daskalov et al. (2006), there, with the help of energy and mass balances, the derivatives of temperature and humidity of the single mixing volume were calculated, whereas the model proposed here has two additional states. Without the roof and floor temperature the dynamics of the interior temperature could not be reproduced sufficiently precise to use them for the MPC controller. The sketch in Figure 3 shows all considered energy and mass flows and indicates the state variables. These are in our modelling approach: the temperature of the single mixing volume $\left(T_{\text {int }}\right)$, the total mass of the water contained in the single mixing volume $\left(m_{w}\right)$ as a measure for the absolute humidity. To take the mass of water contained in the volume instead of any other humidity leads to more clearly arranged equations, as the division by the volume is done in the output equation and not in the state equation. The two other state variables are the temperature of the floor plate ( $\left.T_{\text {floor }}\right)$ and the temperature of the roof $\left(T_{\text {roof }}\right)$.

Figure 3. Energy and Mass Flows in the Broiler House: Inflows with a Positive Superscript, Outflows with a Negative; the State Variables are Represented with Bold Symbols

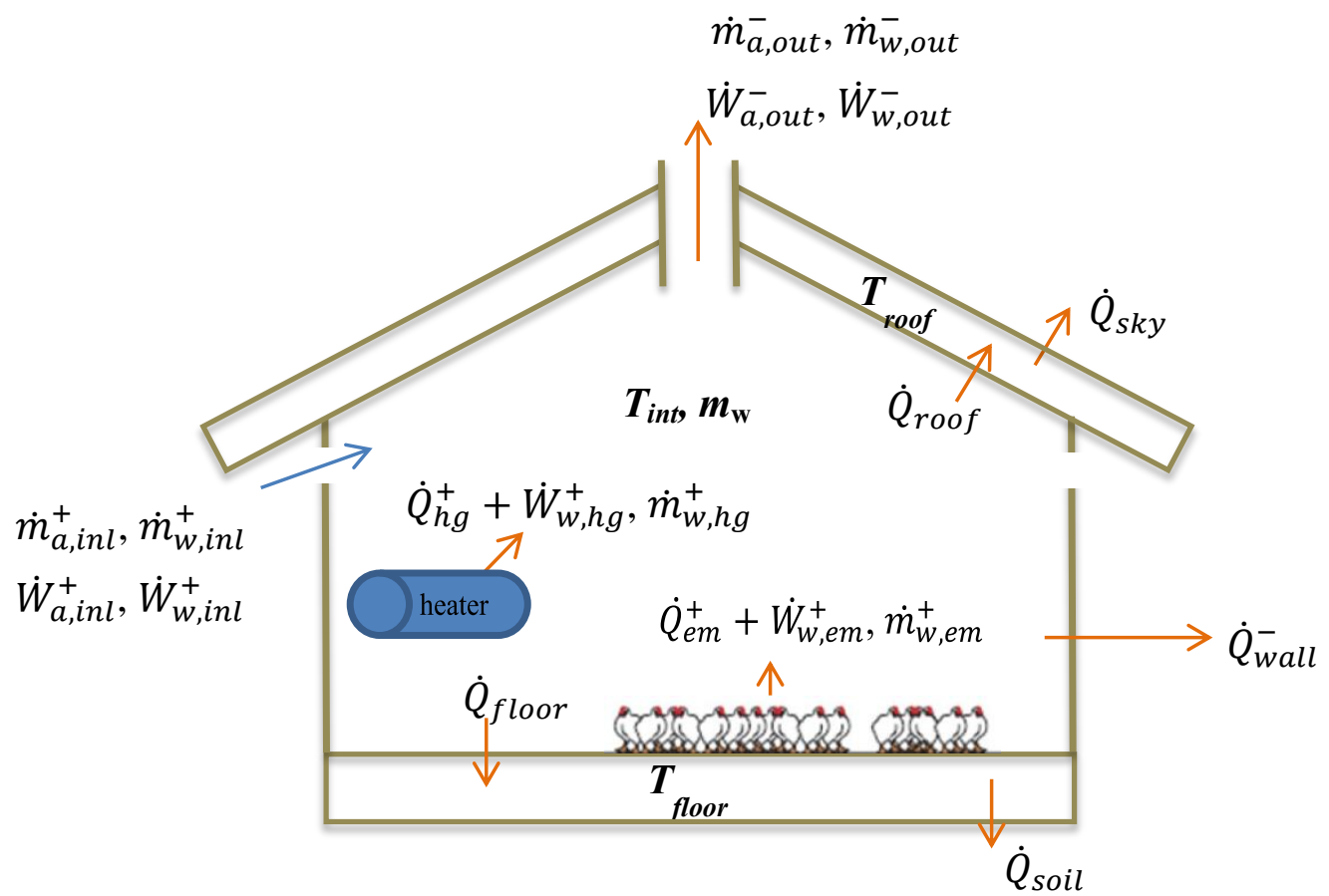




\section{State Variable: Mass of Water in the Broiler House}

To get an expression for the derivative or the mass of the water $\left(m_{w}\right)$ it suffices to calculate the balance of all in- and outflows.

$$
\frac{\mathrm{d}}{\mathrm{d} t} m_{w}=\dot{m}_{w, i n l}^{+}-\dot{m}_{w, o u t}^{-}+\dot{m}_{w, h g}^{+}+\dot{m}_{w, e m}^{+}
$$

All mass flows are indicated in Figure 3: $\dot{m}_{w, \text { inl }}^{+}$and $\dot{m}_{w, \text { out }}^{+}$are masses of the water exchanged with the outside through ventilation, $\dot{m}_{w, h g}^{+}$is the mass of water introduced to the volume through the combustion of the heating gas and $\dot{m}_{w, e m}^{+}$is the mass of water emitted by the animals.

$\dot{m}_{w, \text { inl }}^{+}$and $\dot{m}_{w, o u t}^{+}$can generally be calculated with the available measurements and state variables. First, the mass of the water in the air drawn in by the ventilation is given by the outside humidity.

$$
\dot{m}_{w, i n l}^{+}=w_{e x t} \dot{m}_{a, i n l}^{+}
$$

where $w_{\text {ext }}$ is the external humidity mixing ratio. Then an approximate expression for $\dot{m}_{a, i n l}^{+}$is

$$
\dot{m}_{a, \text { inl }}^{+} \cong \dot{m}_{a, \text { out }}^{-}=\left(\frac{P}{r_{a} T_{\text {int }}}-\frac{r_{w} m_{w}}{r_{a} V_{\text {house }}}\right) \dot{V}_{v e}
$$

and hence

$$
\dot{m}_{w, \text { inl }}^{+} \cong w_{\text {ext }}\left(\frac{P}{r_{a} T_{\text {int }}}-\frac{r_{w} m_{w}}{r_{a} V_{\text {house }}}\right) \dot{V}_{\text {ve }}
$$

where $P$ is the air pressure (assumed constant), $r_{a}\left(r_{w}\right)$ is the specific gas constant of air (water), $T_{\text {int }}$ the measured single temperature of the volume, $V_{\text {house }}$ is the capacity of the mixing volume and $\dot{V}_{v e}$ is the ventilation rate, which is a manipulable input and hence is known. For approximation (3) the fact was used that during the combustion of natural gas the carbon part bound to oxygen does not significantly increase the air mass in the building.

The calculation of the mass flow ejected is straightforward

$$
\dot{m}_{w, \text { out }}^{+}=\frac{m_{w}}{V_{\text {house }}} \dot{V}_{\text {ve }}
$$

The mass flow from the heating is the rather simple expression

$$
\dot{m}_{w, h g}^{+}=\rho_{N, v a p} X_{w} Z \cdot \dot{V}_{h g}
$$


where $\rho_{N, \text { vap }}$ is the density of vaporous water, $X_{w}$ is the stoichiometric yield of water at the heating gas combustion and $Z$ is a proportionality factor taking into account that the heating gas is usually at a higher pressure in the gas pipe. $\dot{V}_{h g}$ is the second manipulable input.

The moisture emitted by the birds $\dot{m}_{w, e m}^{+}$will be determined in the section "Animal Emissions". There, tabled values giving an estimate of the temporal emissions will be calculated using the model developed in this section.

\section{State Variables: Temperature of Roof and Floor}

For the calculation of the temperatures in the roof and the floor, energy balances are formed.

$$
\begin{gathered}
c_{p, \text { floor }} m_{\text {floor }} \frac{\mathrm{d}}{\mathrm{d} t} T_{\text {floor }}=\dot{Q}_{\text {floor }}-\dot{Q}_{\text {soil }} \\
c_{p, \text { roof }} m_{\text {roof }} \frac{\mathrm{d}}{\mathrm{d} t} T_{\text {roof }}=\dot{Q}_{\text {roof }}-\dot{Q}_{\text {sky }}
\end{gathered}
$$

where $c_{p \text {,floor }}$ and $c_{p \text {,roof }}$ are the corresponding specific heat capacities at constant pressure, $T_{\text {floor }}$ and $T_{\text {roof }}$ are state variables. $\dot{Q}_{\text {floor }}$ is the heat flow from the volume into the floor plate and $\dot{Q}_{\text {soil }}$ the heat flow from the floor plate into the soil. Similarly, $\dot{Q}_{\text {roof }}$ and $\dot{Q}_{s k y}$ are the heat transfers from the volume into the roof and from the roof to the outside air. They are all calculated with the help of thermal transmittance values which are estimated with standard tools from building physics. Transmission values for the particular insulation material ${ }^{1}$ are available from the supplier. The values finally obtained for the geometry of the considered broiler house, according to the standards SIA 380 and EN ISO 13370 (Marti 2001), are gathered in Table 1. The radiance is not considered explicitly, when in clear calm nights the roof temperature falls considerably under the ambient temperature, the heat flow might be underestimated, under average conditions the calculated value should match quite well.

$$
\begin{gathered}
\dot{Q}_{\text {floor }}=U_{\text {floor }} A_{\text {floor }}\left(T_{\text {int }}-T_{\text {floor }}\right) \\
\dot{Q}_{\text {soil }}=U_{\text {soil }} A_{\text {floor }}\left(T_{\text {floor }}-T_{\text {ext }}\right) \\
\dot{Q}_{\text {roof }}=U_{\text {ceiling }} A_{\text {roof }}\left(T_{\text {int }}-T_{\text {roof }}\right) \\
\dot{Q}_{\text {floor }}=U_{\text {roof }} A_{\text {roof }}\left(T_{\text {roof }}-T_{\text {ext }}\right)
\end{gathered}
$$

\footnotetext{
${ }^{1}$ Kingspan Selthaan "BriteBoard" and "Mehrlagen"
} 
Table 1. Thermal Transmittances of the Building Elements

\begin{tabular}{|l|c|}
\hline Building Element & Thermal Transmittance $\left[\frac{W}{m^{2} K}\right]$ \\
\hline Floor $\left(U_{\text {floor }}\right)$ & 40 \\
\hline Soil $\left(U_{\text {soil }}\right)$ & 1.237 \\
\hline Ceiling $\left(U_{\text {ceiling }}\right)$ & 0.952 \\
\hline Roof $\left(U_{\text {roof }}\right)$ & 0.231 \\
\hline Wall $\left(U_{\text {wall }}\right)$ & 0.331 \\
\hline
\end{tabular}

State Variable: Temperature of the Air in the Broiler House

The derivation of the equation for the last state variable is more elaborate because some of the heat flows involve mass transport, therefore the product rule has to be observed to calculate the derivative of the inner energy. Apart from this extra step, the procedure is the same: The derivative of the inner energy of the fluid is equal to the sum of the heat flows. In thermodynamics the symbol for the total internal energy is the uppercase $U$, which is in this article already used for the thermal admittance, the symbol for the specific internal energy is the lowercase $u$.

$$
\frac{\mathrm{d} U}{\mathrm{~d} t}=\frac{\mathrm{d}}{\mathrm{d} t}(m \cdot u)=\frac{\mathrm{d}}{\mathrm{d} t}\left(m_{a} u_{a}+m_{w} u_{w}\right)=\sum_{k} Q_{k}+\sum_{l} W_{l}
$$

where exceptionally $U$ is the total internal energy of the fluid within the broiler house volume (and not a thermal admittance). $m$ is the total mass and $u$ is the total specific internal energy of the fluid within the volume, whereas $m_{a}, m_{w}, u_{a}$ and $u_{w}$ are the masses and specific energies of the water and air parts only within the volume. Because of the ventilation, the masses $m_{w}$ and $m_{a}$ are not constant and hence the product rule has to be applied, when $\frac{\mathrm{d} T}{\mathrm{~d} t}$ is to be isolated from $\frac{\mathrm{d} u}{\mathrm{~d} t}$.

For the temperature and pressure ranges that occur in a broiler house the specific internal energy can be expressed in linear form

$$
u=c_{v}\left(T-T_{r e f}\right)+u_{r e f}
$$

$u_{r e f}$ is the total internal energy at the temperature $T_{r e f}$, numerical values can be found in any collection of tables for chemistry (Rumble 2018). With this formula an expression for $\frac{\mathrm{d} T_{\text {int }}}{\mathrm{d} t}$ can be developed. Furthermore, assuming semi-perfect gases for dry air and moisture

$$
\frac{P \cdot V_{\text {house }}}{T_{\text {int }}}=m_{a} r_{a}+m_{w} r_{w}
$$

$m_{a}$ can be eliminated in (13), such that only the state variable $m_{w}$ remains and with the help of the well-known relation 


$$
c_{p}=c_{v}+r
$$

$c_{v}$ can be eliminated. The insertion and transformation of the equations is mere algebra and does not give extensive scientific insight. Therefore, the individual steps are omitted here, and the result is given just below in subsection "Writing the State Space Model".

On the right hand side of (13) is the sum of all heat flows $\left(\sum Q+\sum W\right)$. The heat flows through roof and floor have already been specified in (9) to (12). The heat flow through the walls is calculated the same way. The corresponding thermal admittance for the broiler house in consideration is given along with the others in Table 1.

$$
\dot{Q}_{\text {wall }}^{-}=U_{\text {wall }} A_{\text {wall }}\left(T_{\text {int }}-T_{\text {ext }}\right)
$$

Remaining heat flows shown in Figure 3 but not yet defined are: $\dot{Q}_{h g}^{+}$and $\dot{W}_{w, h g}^{+}$, the sensible and latent heat from the heating, $\dot{W}_{a, i n l}^{+}$and $\dot{W}_{w, i n l}^{+}$, latent heat from the fresh air drawn in by the ventilation, and $\dot{W}_{a, o u t}^{-}$and $\dot{W}_{w, \text { out }}^{-}$, the latent heat blown out by the ventilation. Finally, there are the heat emissions of the birds: $\dot{Q}_{e m}^{+}$is the sensible heat and $\dot{W}_{w, e m}^{+}$is the latent heat contained in the breathing air. In fact, they are both unknown and will be estimated in the next section as a joint quantity.

The sensible heat from the heating is given directly by $\dot{V}_{h g}$, the heating gas supply, which is a manipulable input.

$$
\dot{Q}_{h g}^{+}=Z \cdot H u \cdot \dot{V}_{h g}
$$

where $H u$ is the lower heating value of the heating gas, giving the energy set free by the combustion of a given volume of the heating gas at standard conditions. $Z$ is the same factor as in (6) taking into account that the gas is not at standard conditions in the gas tube.

Additionally, there is the latent heat, which is introduced to the volume by the exhaust of the heating, or more precisely by the vapour contained in the exhausts.

$$
\dot{W}_{w, h g}^{+}=\left[c_{p, v a p}\left(T_{h g}-T_{r e f}\right)+h_{v a p, r e f}\right] \dot{m}_{w, h g}
$$

Where the enthalpy at standard conditions $h_{v a p, r e f}$ can be found in any collection of tables for chemistry (Rumble 2018). It is important to include this term here, as it is measured and taken into account when it is blown out by the ventilation on the other side of the balance, namely by $\dot{W}_{w, o u t}^{-}$. This latter and the other three latent heat flows due to the ventilation are

$$
\begin{gathered}
\dot{W}_{a, \text { inl }}^{+}=\left(c_{p, a}\left(T_{\text {ext }}-T_{\text {ref }}\right)+h_{\text {ref }}\right) \dot{m}_{a, \text { inl }} \\
\dot{W}_{w, \text { inl }}^{+}=\left(c_{p, \text { vap }}\left(T_{\text {ext }}-T_{\text {ref }}\right)+h_{\text {vap }, \text { ref }}\right) \dot{m}_{w, \text { inl }} \\
\dot{W}_{a, \text { out }}^{-}=\left(c_{p, a}\left(T_{\text {int }}-T_{\text {ref }}\right)+h_{\text {ref }}\right) \dot{m}_{a, \text { out }}
\end{gathered}
$$




$$
\dot{W}_{w, \text { out }}^{-}=\left(c_{p, \text { vap }}\left(T_{\text {int }}-T_{\text {ref }}\right)+h_{\text {vap }, \text { ref }}\right) \dot{m}_{w, \text { out }}
$$

\section{Writing the State Space Model}

Combining the equations from the previous section, after a considerable amount of paperwork the following state space model can be written.

$$
\begin{aligned}
& \frac{\mathrm{d} T_{\text {int }}}{\mathrm{d} t} \cdot\left[m_{w} c_{p, v a p}+\left(\frac{P V_{\text {house }}}{T_{\text {int }} r_{a}} \frac{T_{\text {ext }}}{T_{\text {int }}}-\frac{r_{w}}{r_{a}} m_{w}\right) c_{p, a}\right]= \\
& -\left(\dot{m}_{w, e m}^{+}+\rho_{N, v a p} X_{w} Z \dot{V}_{h g}\right)\left[h_{\text {vap }, r e f}+c_{p, v a p}\left(T_{i n t}-T_{r e f}\right)-\frac{r_{w}}{r_{a}} c_{p, a}\left(T_{i n t}-T_{e x t}\right)\right] \\
& +Z \cdot H u \cdot \dot{V}_{h g}+\left[c_{p, v a p}\left(T_{h g}-T_{\text {ref }}\right)+h_{\text {vap }, \text { ref }}\right] \rho_{N, v a p} X_{w} Z \cdot \dot{V}_{h g} \\
& -U_{\text {floor }} A_{\text {floor }}\left(T_{\text {int }}-T_{\text {floor }}\right)-U_{\text {roof }} A_{\text {roof }}\left(T_{\text {int }}-T_{\text {roof }}\right) \\
& -U_{\text {wall }} A_{\text {wall }}\left(T_{\text {int }}-T_{\text {ext }}\right) \\
& -\left(\left(w_{\text {ext }}\left(\frac{P}{r_{a} T_{\text {int }}}-\frac{r_{w} m_{w}}{r_{a} V_{\text {house }}}\right)\left(\frac{c_{p, v a p}}{c_{p, a}}-\frac{r_{w}}{r_{a}}\right)+\frac{P}{r_{a} T_{\text {int }}}\right) \dot{V}_{v e}\right) c_{p, a}\left(T_{\text {int }}-T_{\text {ext }}\right) \\
& +\dot{Q}_{e m}^{+}+W_{w, e m}^{+} \\
& \frac{\mathrm{d} m_{w}}{\mathrm{~d} t}=+m_{w, e m}^{+}+\rho_{N, v a p} X_{w} Z \cdot \dot{V}_{h g}+\left(\frac{w_{\text {ext }} P}{r_{a} T_{\text {int }}}-\frac{\left(w_{\text {ext }} r_{w}+r_{a}\right) m_{w}}{r_{a} V_{\text {house }}}\right) \dot{V}_{v e} \\
& \frac{\mathrm{d} T_{\text {floor }}}{\mathrm{d} t} c_{p, \text { floor }} m_{\text {floor }} \\
& =U_{\text {floor }} A_{\text {floor }}\left(T_{\text {int }}-T_{\text {floor }}\right)-U_{\text {soil }} A_{\text {floor }}\left(T_{\text {floor }}-T_{\text {ext }}\right) \\
& \frac{\mathrm{d} T_{\text {roof }}}{\mathrm{d} t} c_{\text {p,roof }} m_{\text {roof }} \\
& =U_{\text {ceiling }} A_{\text {roof }}\left(T_{\text {int }}-T_{\text {roof }}\right)-U_{\text {roof }} A_{\text {floor }}\left(T_{\text {roof }}-T_{\text {ext }}\right)
\end{aligned}
$$

With the above state equation (24) to (27), the output equation becomes

$$
\left[\begin{array}{l}
T_{\text {int }} \\
a_{\text {int }}
\end{array}\right]=\left[\begin{array}{cccc}
1 & 0 & 0 & 0 \\
0 & \left(V_{\text {house }}\right)^{-1} & 0 & 0
\end{array}\right] \cdot\left[\begin{array}{llll}
T_{\text {int }} & m_{w} & T_{\text {floor }} & T_{\text {roof }}
\end{array}\right]^{T}
$$

This is a nonlinear state space model with the state variables $T_{\text {int }}, m_{w}, T_{\text {floor }}$ and $T_{\text {roof }}$. The manipulable inputs are $\dot{V}_{h g}$ and $\dot{V}_{v e}$. Measured disturbance inputs are $T_{\text {ext }}$ and $w_{\text {ext }}$. All other symbols are parameters, except $\dot{Q}_{e m}^{+}$and $W_{w, e m}^{+}$, which are to be determined in the next section.

It has been stated above that the layering of the air will probably have an impact on the ventilation. Daskalov et al. (2006) used the concept of the "active mixing volume" to reflect such effects. Here it is proposed to simply consider shortcuts in the ventilation streams and to scale the ventilation rate accordingly. So, in the equation above, $\dot{V}_{v e}$ is not the measured ventilation rate, but a scaled variant of it.

$$
\dot{V}_{v e}=c_{\text {bypass }} \cdot \dot{V}_{\text {ve,meas }}
$$

Using plumes such an effect is made visible, or for other types of buildings CFD simulations have been used (Awwad et al. 2017). The numerical value was determined when the animal emissions -described below- were calculated. 


\section{Model Predictive Control}

The basic idea behind model predictive control is to use a mathematical model of the plant (i.e. the broiler house) to predict its behaviour. An objective function is used to assess, how well the current setting performs. The current setting includes all measurable disturbances, all manipulable input signals, and the constant parameters to the model. Finally, the objective function is minimised by an optimisation. As a result of the optimisation, the optimal input signals up to the horizon (a design parameter of the algorithm) are known. The first sample or period of the input signals is used as input to the plant, the rest of the signal is rejected, because after the calculation new measurement signals are known and taken into account during optimisation for the next sample.

Model predictive control is well established in process control. A considerable number of commercial packages is available for standard applications (Camacho and Bordons 2007). Most of the commercial packages use a black box model to describe the plant. The model is identified with measurement data. The use of a linear (black box) model generally allows to write an explicit control law. The disadvantage is of course the lack of transparency and in case of an underlying non-linear system performance and stability problems may occur.

The equations obtained above show clearly a non-linear system. Furthermore, the time constants of the building are rather slow in comparison to mechatronic or electronic systems, which are also often addressed by the commercial MPC packages. Because of the high level of transparency, we decided to implement a model predictive control with the above first-principles model, a gradient descent algorithm for the optimisation and a cost function allowing for short term setpoint deviations.

\section{Gradient Descent Algorithm}

It is not to expect that the cost function shows pronounced local minima. Indeed, the dependence on the heating gas supply is strictly monotonically increasing, the terms with the mean squared error (weights $q_{1}$ and $q_{2}$ ) are not expected to show any more than one minimum, increasing the temperature deviation always leads to an increase of the cost function. The average terms of the cost function may have more than one solution for the minimum, heating more at one time may be compensated by heating less at another time. Nevertheless, the solutions are not expected to be disjoint, so no local minima should occur. This is a working assumption and not a proof, in case the MPC should be industrialised in this application, the working assumption should be rechecked. The gradient descent was implemented upon this working assumption.

The input functions were parameterised with 4 parameters each. To that end they were split in four intervals: [0 min, 9min], [9min, 21 min], [21min, 120min) and [120min, 12h]. The parameters are the duty cycles for ventilation and heating for each interval. The parameter vector becomes then $\theta=\left[\begin{array}{llllllll}\delta_{V, 0 . .8} & \delta_{H, 0 . .8} & \delta_{V, 9.20} & \delta_{V, 9.20} & \delta_{V, 21.119} & \delta_{H, 21.119} & \delta_{V, 120 . h} & \delta_{V, 120 . h}\end{array}\right]$.

To evaluate the gradient, the cost function was evaluated at positions $\varepsilon$ away from the current parameter vector $\theta$. This evaluation step had different sizes 
depending on the parameter varied: $\varepsilon=\left[\begin{array}{llllllll}0.02 & 0.02 & 0.02 & 0.02 & 0.02 & 0.02 & 0.01 & 0.01\end{array}\right]$, the units being "parts of duty cycle". The step size for descent $\gamma$ finally used, was $\gamma=\left[\begin{array}{llllllll}12 & 15 & 12 & 15 & 6 & 12 & 15 & 30\end{array}\right] \cdot 10^{-6}$.

The gradient descent was run once a minute, giving new duty cycles for the next minute. In the current implementation it did run somewhat faster than real time on a current desktop computer.

\section{Cost Function}

The cost function had to be implemented carefully for our purposes, as it should not penalise short term deviation from the setpoints, however it has to assure that the average values of humidity and temperature converge to the setpoints and that humidity and temperature stay within the comfort region. Furthermore, solutions with high energy consumptions should be penalised. We made simulations with a cost function comprising five terms.

The penalising of the energy consumption was implemented in a straightforward manner. The cost function includes a weighted term with the accumulated heating gas supply. This is the last term with weight $q_{5}$ in (30). Solutions with comparable deviation from the setpoints but with higher energy consumption will henceforth be avoided by the optimisation algorithm.

To avoid that the temperature shows swings harmful to the comfort of the birds, a term was added to the cost function, which gets high whenever the temperature deviates too far away from the setpoint, even when it is only for an instant. The implementation of that term went out at scaling the difference between the measurement and the setpoint with a tolerance $\Delta_{T, a b s}$ before calculating its square value. From that intermediate result, the mean value was calculated and weighted with a weight $q_{1}$. The term looks only into the future, as changing the future temperature cannot compensate for harm made in the past, or in other words, the error can only increase if a larger observation period is chosen. Furthermore, the term takes into account the complete prediction horizon $t_{h o r}$, there is no sense to consider possible solutions, where the temperature is set inadmissibly high even in the far future.

A similar term was instantiated for the humidity. This is the term with the weight $q_{2}$ and the tolerance $\Delta_{h u m, a b s}$ in (30). $\Delta_{T, a b s}$ and $\Delta_{h u m, a b s}$ are chosen such that rather large temperature and humidity swings are possible.

To ensure that the mean value is close to the setpoints, two further terms one for temperature one for humidity - are added to the cost function where the squaring takes place after the averaging. These are the terms with weights $q_{3}$ and $q_{4}$. They have tolerances $\Delta_{T, \text { mean }}$ and $\Delta_{\text {hum,mean }}$ and the averaging takes place over the intervals $\left[-t_{T}, t_{T}\right]$ for the temperature and $\left[-t_{a}, t_{a}\right]$ for the humidity.

$$
J=\frac{q_{1}}{t_{\text {hor }}} \int_{0}^{t_{\text {hor }}}\left(\frac{T_{\text {int }}-T_{\text {set }}}{\Delta_{T, a b s}}\right)^{2} d \tau+\frac{q_{2}}{t_{\text {hor }}} \int_{0}^{t_{\text {hor }}}\left(\frac{a_{\text {int }}-a_{\text {set }}}{\Delta_{\text {hum }, a b s}}\right)^{2} d \tau
$$




$$
\begin{aligned}
& +\frac{q_{3}}{2 t_{T}}\left[\int_{-t_{T}}^{t_{T}} \frac{T_{\text {int }}-T_{\text {set }}}{\Delta_{T, \text { mean }}} d \tau\right]^{2}+\frac{q_{4}}{2 t_{a}}\left[\int_{-t_{a}}^{t_{a}} \frac{a_{\text {int }}-a_{\text {set }}}{\Delta_{\text {hum }, \text { mean }}} d \tau\right]^{2} \\
& +\frac{q_{5}}{t_{\text {hor }}} \int_{0}^{t_{\text {hor }}} \frac{u_{2}(\tau)}{\Delta_{\text {hg }}} d \tau
\end{aligned}
$$

Apparently there has not been a large scientific interest in how resistant broilers are against temperature and humidity deviations, therefore it was difficult to find appropriate values for $t_{T}, t_{\text {hum }}, \Delta_{T, \text { mean }}$ and $\Delta_{\text {hum,mean }}$. After discussions with farmers and scientists in the field of poultry production, we opted for the values in Table 2 . The weights $q_{1}$ to $q_{5}$ finally found through trial and error are also gathered in Table 2 .

\begin{tabular}{|c|c|c|}
\hline & Name & Value \\
\hline \multirow{3}{*}{$\stackrel{\mathscr{Z}}{\stackrel{\Xi}{\Xi}}$} & $t_{\text {hor }}$ & $(12 \mathrm{~h}) 43,200 \mathrm{~s}$ \\
\hline & $t_{T}$ & $(15 \mathrm{~min}) 900 \mathrm{~s}$ \\
\hline & $t_{\text {hum }}$ & (12h) $43,200 \mathrm{~s}$ \\
\hline \multirow{5}{*}{ 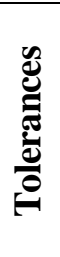 } & $\Delta_{T, a b s}$ & $6 \mathrm{~K}$ \\
\hline & $\Delta_{\text {hum,abs }}$ & $0.53 \mathrm{~kg} \mathrm{~m}^{-3}$ \\
\hline & $\Delta_{T, \text { mean }}$ & $0.5 \mathrm{~K}$ \\
\hline & $\Delta_{\text {hum, mean }}$ & $0.036 \mathrm{~kg} \mathrm{~m}^{-3}$ \\
\hline & $\Delta_{h g}$ & $10^{-3} \mathrm{~m}^{3}$ \\
\hline \multirow{5}{*}{ 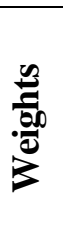 } & $q_{1}$ & $30 s^{0}$ \\
\hline & $q_{2}$ & $30 \mathrm{~kg}^{0} \mathrm{~m}^{0}$ \\
\hline & $q_{3}$ & $144 K^{0}$ \\
\hline & $q_{4}$ & $1125 \mathrm{~kg}^{0} \mathrm{~m}^{0}$ \\
\hline & $q_{5}$ & $10 \mathrm{~m}^{0}$ \\
\hline
\end{tabular}

Table 2. Parameters of the Cost Function

\section{Results}

\section{Animal Emissions}

Intentionally, the model in (24) to (27) should calculate and predict its state variables. This will only work, though, when the exact time dependent animal emissions are known. Pedersen and Sällvik (2002) show courses of those emissions for different animals and also for broilers at age three to five weeks, but not for younger or older broilers. On the other hand, from the food supply and the knowledge on the metabolism, the released energy can be calculated. However, in such a way only an average value is obtained, as the energy is not freed immediately after food intake but can be stored in the birds' bodies over a few hours or even days. 
The solution to this dilemma is to take the model just derived and run it with measurements from measured fattening periods, an approach also used by Cordeau and Barrington (2010). With $T_{\text {int }}$ measured and known, (24) can be transformed to give the unknown sum $\dot{Q}_{e m}^{+}+W_{w, e m}^{+}$. The moving average value of the emissions should then correspond to the value that can be calculated with the help of the food supply. The procedure is illustrated with Figures 4 and 5. In Figure 4 all measured or known heat flows are shown as a thin line and for orientation the light is shown as a dotted line. When the line is high, the light is on, when the line is low, the light is off. The sum of all solid and thin lines is shown as a thick green line. In case of a correct model and low measurement errors, the thick green line gives the heat emissions of the animals $\left(\dot{Q}_{e m}^{+}+W_{w, e m}^{+}\right)$.

Figure 4. Balance of the Heat Flows and Rest Term

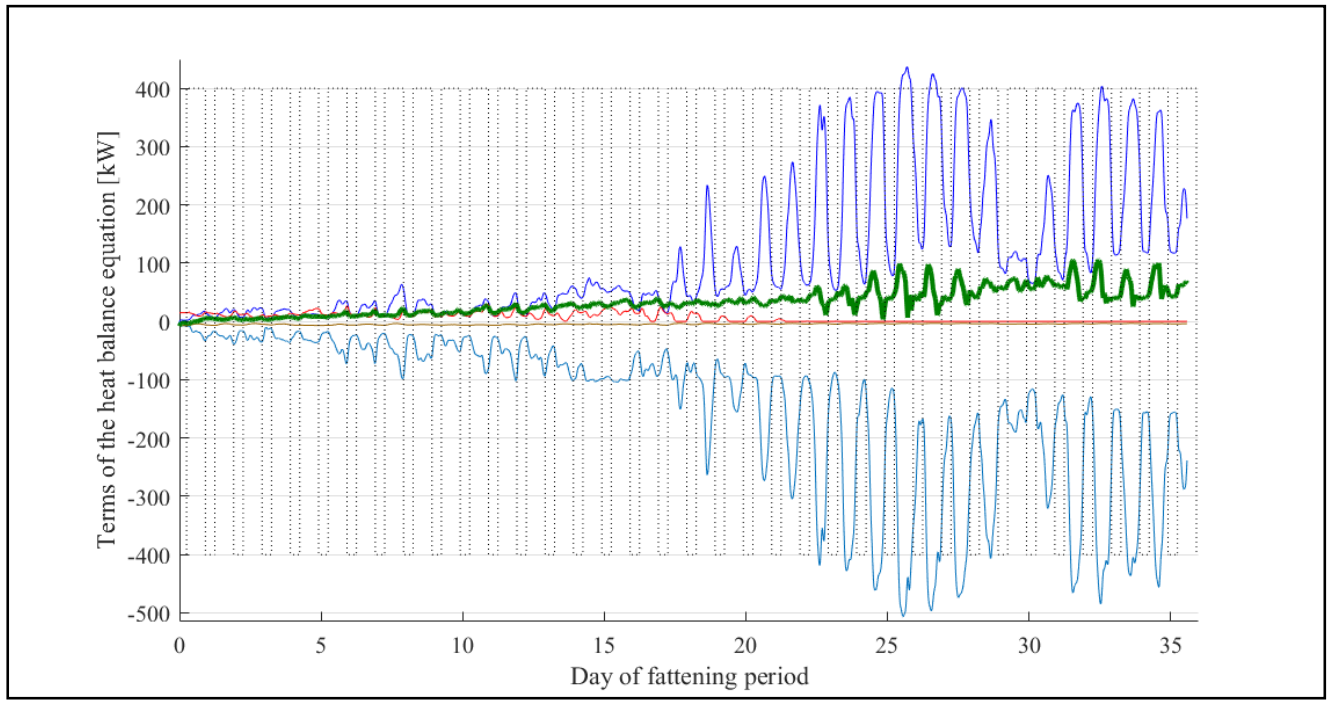

The dotted line shows when the light is switched on and off. The upper blue line shows the energy carried into the broiler house with the fresh air taken in. The cyan line (lowermost) shows the energy lost to the outside through the air blown out by the ventilation. The red line shows the energy supplied by the heating, the brown line the energy lost by transmission through the walls. Finally, the green line is the rest, i.e. the heat emission of the birds.

The rest term can now be compared to the heat emissions that can be obtained from food supply. As has been stated, the values obtained through food supply do not have a good temporal resolution. For their calculation values from Nukreaw and Bunchasak (2015) have been used. With the help of this graph, the value for $c_{\text {bypass }}$ in (29) could be chosen to 0.8 for the broiler house in consideration, this value gave the best match between the average emissions measured through the ventilation and those calculated through food supply. Figure 5 shows the good match between the balance of the heat equation and the emissions estimated from food supply. 
Figure 5. Comparison of the Calculated Heat Emissions from Food Supply and of the rest of the Balance of the Ventilation

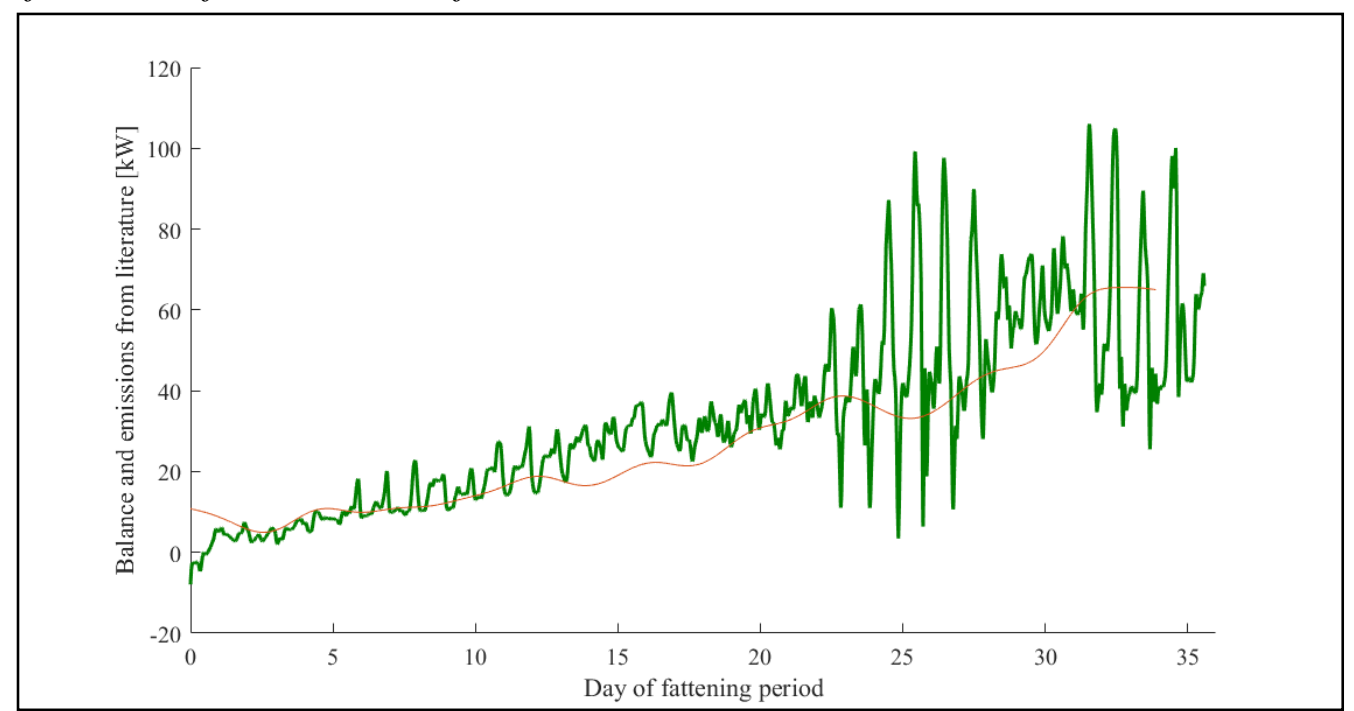

Green: Rest of the balance (from Figure 3), red: Values calculated from birds' weight and food supply.

Data from two fattening periods where used to abstract average courses of the emissions for the emitted heat and moisture. Both were normalized with respect to the weight of the birds. The results are shown in Figures 6 and 7. These data were used for the simulation of the model with state space description in (24)-(27). The data have been made publicly available ${ }^{2}$.

Figure 6. Energy Emissions

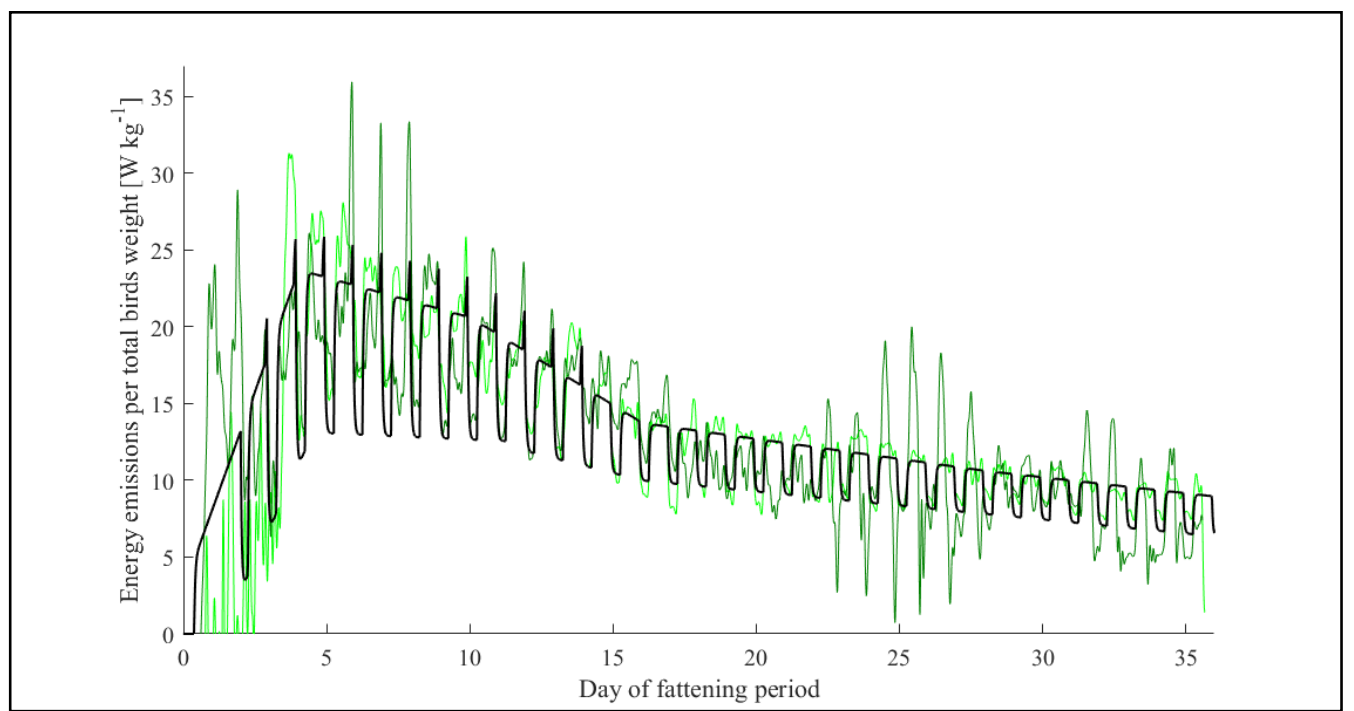

The black line represents the abstracted average courses of the energy emissions, the green lines are measurement data from two fattening periods.

${ }^{2}$ doi:10.17632/dmfbv3wff4.1. 
Figure 7. Moisture Emissions

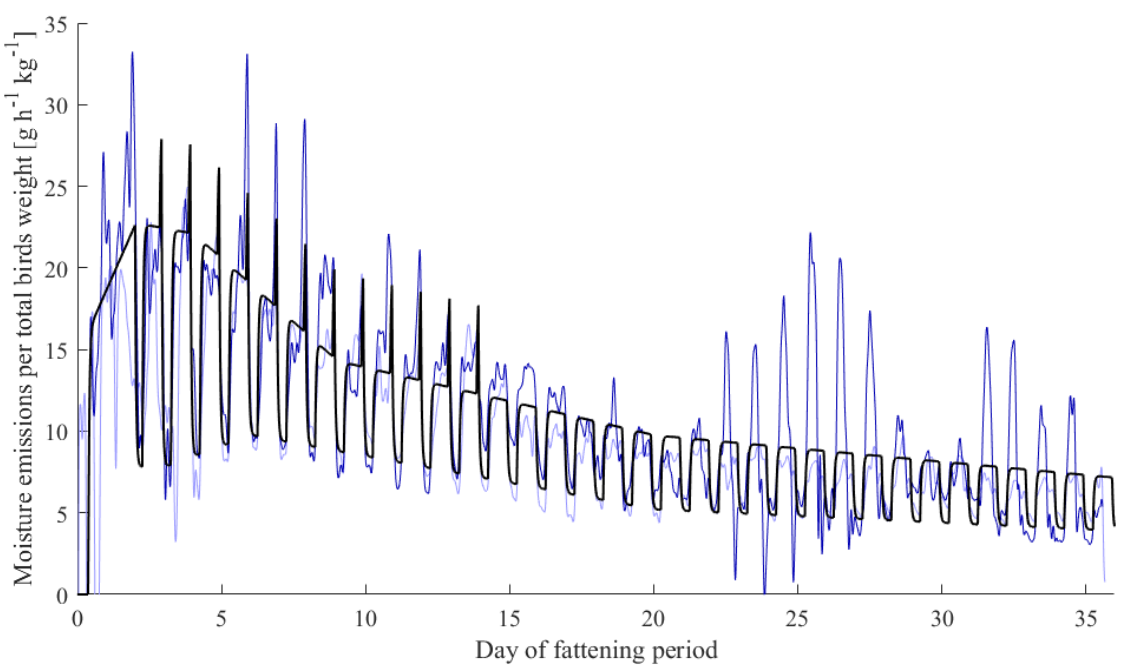

The black line represents the abstracted average courses of the moisture emissions, the blue lines are measurement data from two fattening periods.

\section{Model Validation}

To validate the model, it was hooked up to the recorded control signals of the installed controller and the simulated signals were compared to the measured signals. The result is shown with the coloured lines in the central and lower plot of ; it shows the simulation of a random hour of a fattening period compared to the measurements of this particular hour. The simulation was made with the estimated and abstracted animal emissions, which may differ from the momentary emissions in the broiler house. For this particular hour apparently the heat emissions were lower than estimated, hence the simulated temperature was a few degrees lower. For better comparison it has been shifted upwards. Generally, the simulation reproduces the dynamical behaviour of the broiler house very well; the size of the temperature and humidity swings is comparable to the measurements.

\section{Performance of the MPC}

Both, a replication of the installed control algorithm and the model predictive control were used to control the simulation model. So even if there are imperfections in the model, the result will we be due to the difference in the control algorithms, as animal emissions and weather conditions are perfectly equal in both simulations. Weather conditions were taken from measurements and animal emissions were taken from our calculations. The data reproduce the $16^{\text {th }}$ day of a fattening period we measured in January 2015. Heating requirements are most important around that day in the fattening period because humidity is still required to be rather low and temperature rather high (Aviagen Technical Team, 2014). The red line in Figure 4 indicates this circumstance.

Typical time courses of the internal temperature $T_{1}$ and absolute humidity $a_{\text {int }}$ are shown in Figures 8 and 9. In both figures, the awakening of the birds is 
very apparent: At 6 o'clock, when the light is switched on, the birds produce considerably more emissions than before, which leads to a temperature and humidity increase. Both controllers react very differently to this perturbation. The replicated controller seeks to immediately correct the humidity difference and hence increases immediately the ventilation duty cycle, which in turn has a major impact on the temperature, which first increases but then sinks below the setpoint due to the accrued ventilation.

Figure 8. Comparison of Temperature Courses with MPC and Original Control

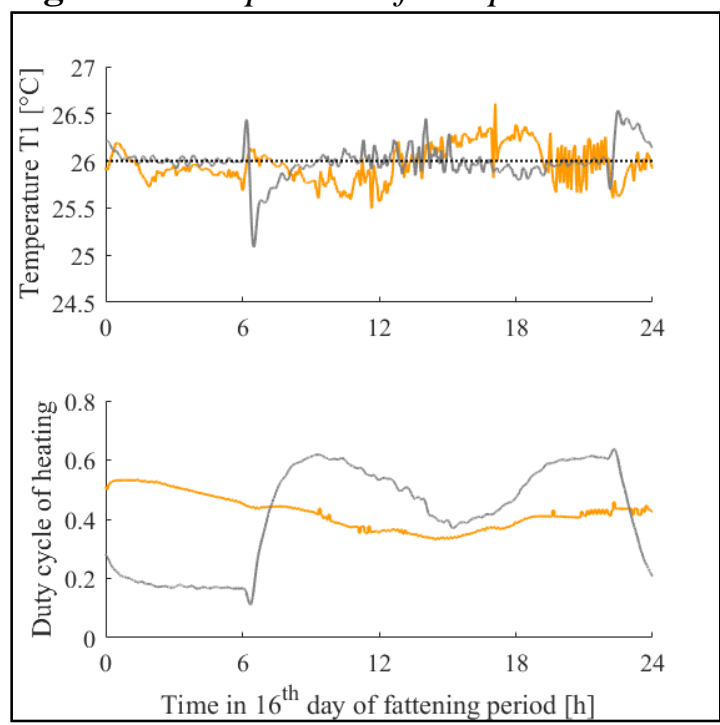

The dotted line shows the setpoint of the temperature, the grey line shows the simulated temperature with the replicated controller and the orange line shows the simulated temperature in case of MPC control. The lower plot shows the controller output of both controllers with the same colours.

Figure 9. Comparison of Humidity Courses with MPC and Original Control

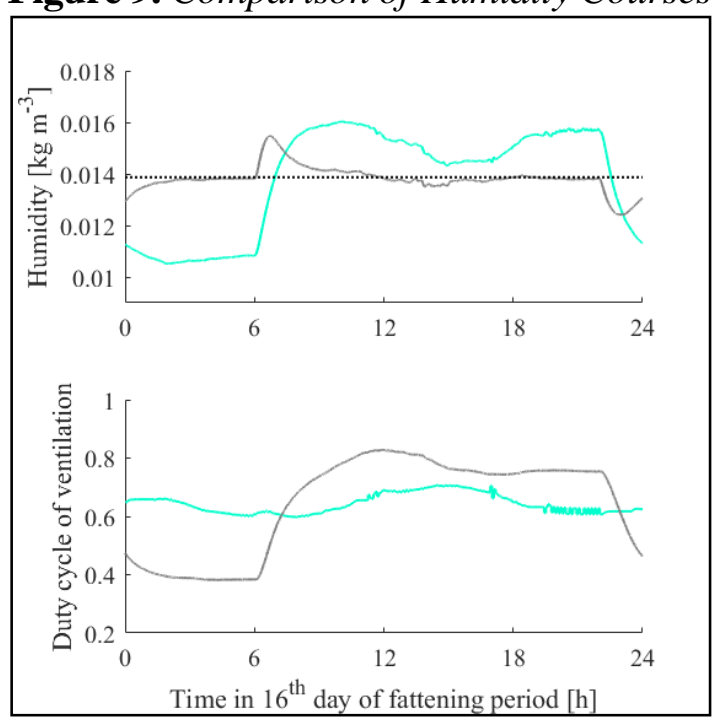

The dotted line shows the setpoint of the humidity (mean humidity in case of MPC), the grey line shows the simulated temperature with the replicated controller and the cyan line shows the simulated temperature in case of MPC control. The lower plot shows the controller output of both controllers with the same colours. 
The time courses of the MPC show a different behaviour. Because of the averaging in the cost function, the duty cycles vary only slowly. As a consequence, the humidity depends strongly on the emissions of the birds. Looking more closely at the duty cycle of the MPC algorithm, it can be seen that in the late afternoon, when outside temperature is high and humidity is low, MPC increases the ventilation duty cycle. This suggests that the general idea behind the MPC works: Ventilation is used more when it is cheap. For the day shown in the above figures, the energy saving was at $2 \%$. Figure 10 shows the cumulative heating gas consumption. As MPC varies the duty cycles only smoothly, it first consumes much more energy than the replicated controller. Later, though, when the replicated controller invests a lot to keep the broiler house dry, the MPC has an advantage.

Figure 10. Cumulative Heating Gas Consumption for MPC and the Replicated Controller

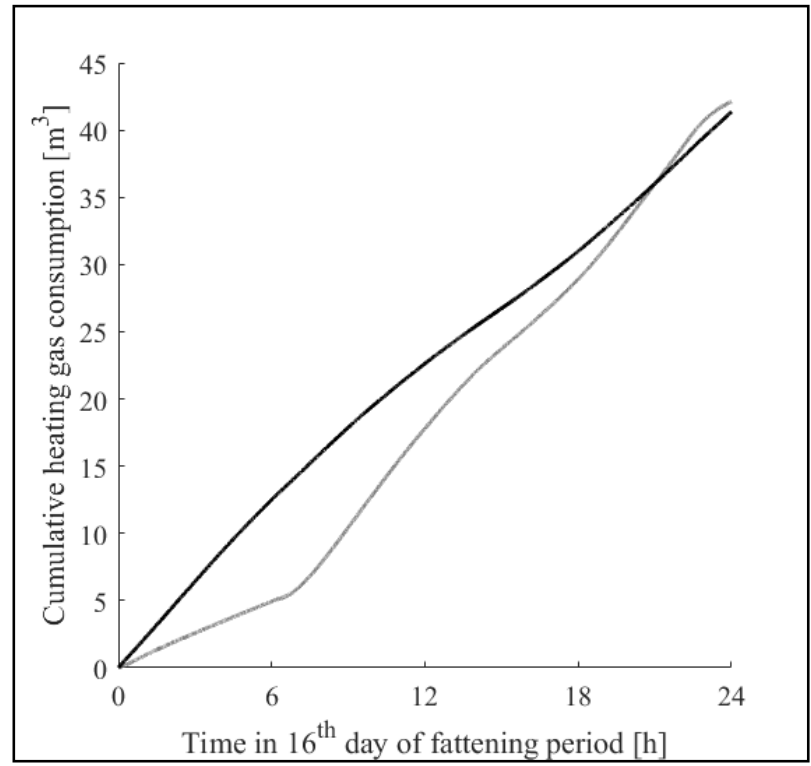

The grey line shows the replicated controller consumption, the black line the consumption with MPC.

Nevertheless, it is difficult to interpret the time courses of the MPC; is this, the best result that can be achieved or is the MPC just stolid or are maybe its parameters unfavourable? To narrow down the possibilities, the model was used in a less intended use.

\section{Effect of Varying Humidity on Energy Consumption}

To quantify the effect of varying the humidity on energy consumption some additional simulations were made. For the particular day already investigated above, the relative humidity was held constant (unlike in the MPC strategy but like in the original control strategy) and once increased by a determined amount and another time decreased by the same amount. The idea behind was, that if the humidity was lowered during a certain time interval and raised by the same 
amount in the next equally long interval, the mean humidity would be equal to the case of unmodified constant humidity. If the energy consumption would differ in both cases, then this would be ground to spare or waste energy.

Figures 11 and 12 show the energy consumptions for the different cases. Figure 11 shows the case where humidity was increased and decreased by $20 \%$ starting from $50 \%$ relative humidity. In the figure the absolute humidity is given to be consistent. It can be seen in the figure that quite an amount of heating gas has to be supplied additionally if the broiler house has to be maintained at a very dry level: The red line is almost an order of magnitude higher than the black line. The green line, which corresponds to a more humid broiler house, is on its turn far below the black line, but at no instant the energy spared (when occasionally not drying the broiler house as much as on average) is larger than the energy additionally expended when drying the broiler house more to correct the average humidity. This is illustrated in the lower half of the figure, it shows the difference between the red and the black line as a red line and the difference of the green and the black line as a green line: There is no time instant at which the energy spared (green) is above the energy expended (red). Hence, in varying the humidity in such a way does not allow for savings but leads to additional costs.

Figure 11. Heating Gas Consumption during One Day of Fattening Period for a $20 \%$ Increased and Reduced Humidity

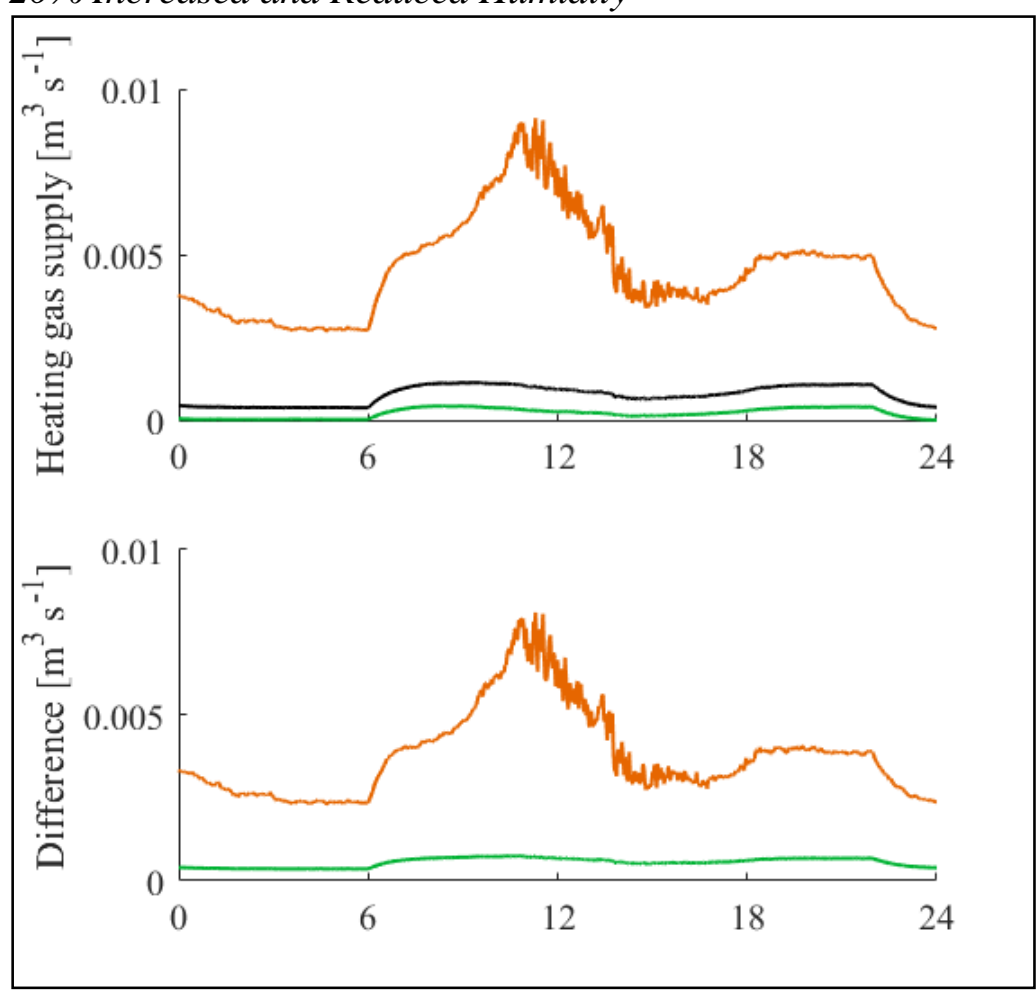

The black line shows the consumption for 50\% relative humidity, the red line shows the consumption for $30 \%$ relative humidity and the green line shows $70 \%$ relative humidity. The lower plot shows the differences of the red and the black line above as a red line and the black and the green line above as a green line. 
Figure 12. Heating Gas Consumption during One Day of Fattening Period for a $3 \%$ Increased and Reduced Humidity

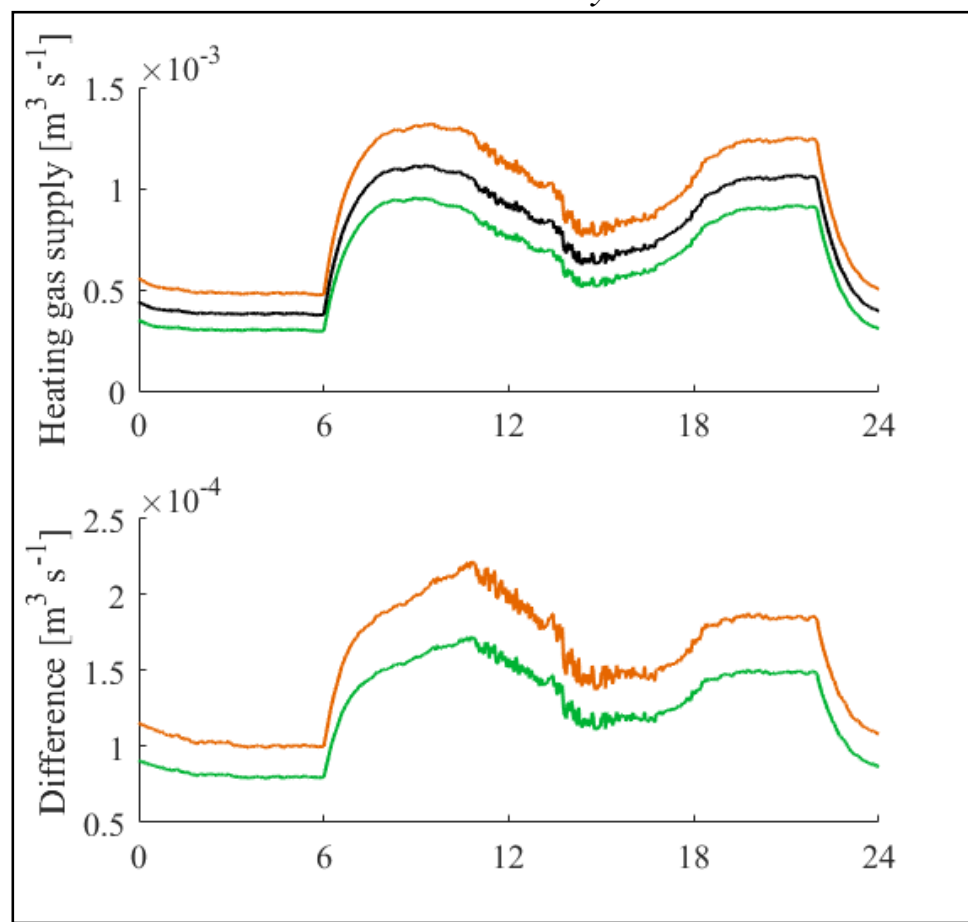

The black line shows the consumption for 50\% relative humidity, the red line shows the consumption for $47 \%$ relative humidity and the green line shows $53 \%$ relative humidity. The lower plot shows the differences of red and the black line above in red and the black and the green line above in green.

Increasing and decreasing the humidity by $50 \%$ is of course large-scale. Figure 12, on the other hand, shows the same calculations for a less heavily modified humidity. From the lower part of the plot it can be seen that increasing the humidity between 11 and 12 o'clock would lead to heating gas savings and if the humidity would be decreased between 5 and 6 o'clock, then the average humidity would still be the same and the additional gas supply between 5 and 6 o'clock would be less than the savings: Between 5 and 6 o'clock the red line is below the green line between 11 and 12 o'clock.

Repeating this scenario for several humidity levels and taking the extreme points in the graph, an upper bound for the possible heating gas savings can be given. Figure 13 shows the result of such an analysis. With an increase and decrease of $5 \%$ of the humidity the theoretical savings are maximised. They are around $5.9 \%$. It is stressed here that this is a theoretical value, which does not exist in practice, because it reduces the day to a best and a worst point. 


\section{Discussion}

Figure 1 shows that the accuracy of the model is enough to display the dynamics of the broiler house. Heating and ventilation have a first order dependence on the temperature $T_{1}$ and the humidity represented as $m_{w}$ in the model. Furthermore, the model knows only one temperature and one humidity for the entire Volume, whereas the physical broiler house shows a layering and a more complex dependence on the heating and the ventilation. However, the amplitudes of the heating and ventilating pulses are similar in both cases and even in the measured signals, the slope changes rather fast, when the heating or the ventilation is turned on or off.

The MPC had then the task to find these particular heating and ventilation input functions which minimise the cost function. The MPC had at its disposition the model as well as the measured and forecasted disturbance inputs, but no specific lead to where it had to search to minimise the energy consumption was given. One property of the found input function would be the offset between ventilation and heating: Is it more economic to ventilate before heating or contrariwise? However, for such a minimisation to work, the accuracy of the model would need to be in the range of a few seconds, which does not appear to be the case in Figure 1. Therefore, this parameter was not part of the minimisation. Another property is the humidity modulation: Make it more humid during some occasions and dryer during others. But beside these two properties we thought of, the MPC could have found any other property, leading to energy savings.

The interpretation of the minimisation result is hard to do. Because of the averaging in the cost function the control signals (ventilation flow rate and heating gas supply) change only slowly over time (Figures 8 and 9). It is noticeable that both signals have a rather high value early in the morning compared to their mean value and their counterparts of the replicated control at the same time. This is surprising because outdoor temperature is low at that time and one would suspect the heating to be expensive. The behaviour is consistent, though, with Figure 12. It does cost only little additional heating gas to keep the air at a dryer level before the birds are awake, then when the birds are awake and produce emissions, but the outside temperature is still low, it is most expensive to ventilate. Around noon when outside temperature is finally high, it is again cheaper to ventilate (still maintaining temperature at comfort level). This is the main reason why the energy savings are limited with such a control strategy: The birds themselves do it already right, they produce the moisture emissions for the most part when it is warm outside.

The MPC appears to better track the setpoint temperature in front of the perturbation because of the birds' emissions around 6 o'clock. Close inspection of the control signals reveals however, that this is not so much because of anticipatory setting of the control signals but rather the result of the averaging in the cost function. The replicated control reacts to the birds' emissions and changes both the heating gas supply and the ventilation rate, because the ventilation rate has a coupling effect on temperature, the temperature control is exposed to a major disturbance and needs to significantly increase the heating gas supply. Because the 
MPC does not immediately change the ventilation rate, there is no such effect on the temperature, and it tracks the setpoint better.

Finally, the energy savings of the MPC of around 2\% appear reasonable in front of the investigation disclosed in Figure 13. It cannot be excluded that a different parameterization of the optimisation algorithm would lead to another percent gain in energy savings, but the order of magnitude is right.

Figure 13. Maximal Possible Heating Gas Savings from Humidity Modulation, if the Exterior Conditions would be in Best Case during Half of the Time and in Worst Case during the Other Half

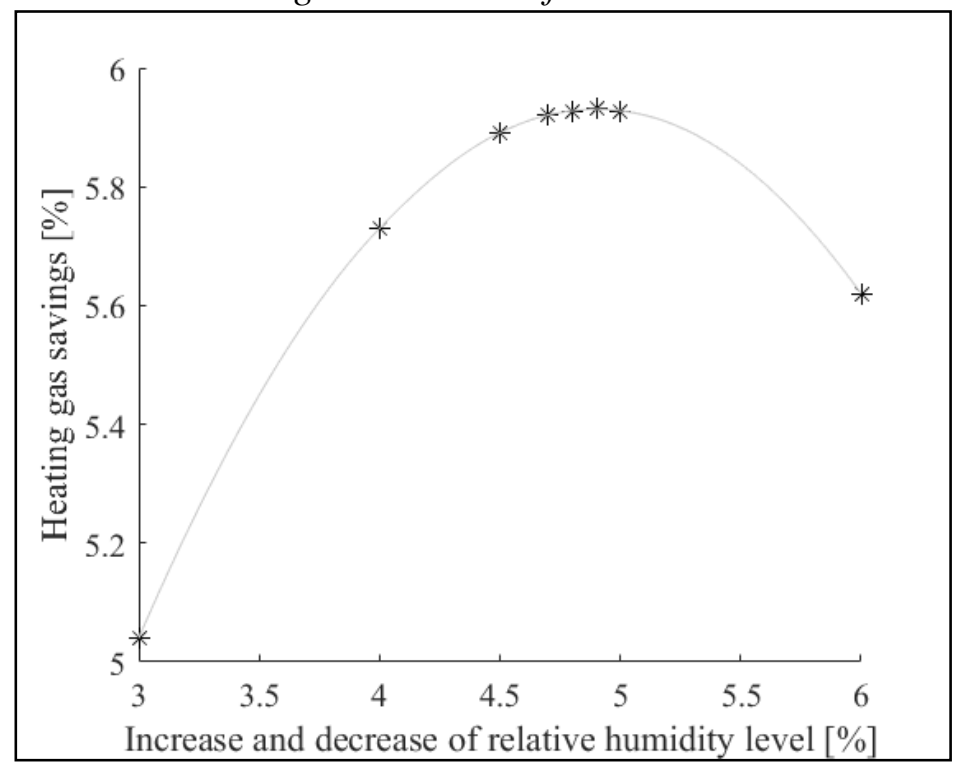

\section{Conclusions}

It was shown that MPC can be used to allow for short term deviations from the setpoints for humidity and temperature. A cost function specifically designed for this purpose was proposed and the result of $2 \%$ energy reduction for a $24 \mathrm{~h}$ period at a particular day in winter was obtained. If this perspective is enough for operators of broiler houses to modify their control algorithms is a decision of business strategy. From a scientific viewpoint, the result was checked for reasonability and bounded. An aspect that still needs to be taken into account, however, is that our calculations were built on a numerically exact model. Effects of robustness have not been investigated.

One of the factors why the result is less than could have been expected, when considering similar techniques for human buildings, is the fact that broiler houses accommodate considerably more occupants. The emissions are consequently important and the strategy that the MPC mainly uses (to ventilate predominantly when costs are low), can only limitedly be used, because of excessive humidity build up. Furthermore, it has shown that increasing or decreasing the humidity temporarily yields to important additional costs compared to a constantly regulated humidity. Apparently, apart from modulating the humidity -and in a much more 
restricted way also the temperature- there is no easy way to save heating energy in the broiler house.

The achievable energy reduction will depend strongly on climatic conditions. The investigations carried out were focused on climatic conditions found at Swiss Plateau. When the outside temperature swings are more important and outside humidity is generally low, the result may be more favourable. Additionally, when the lighting does not follow a $24 \mathrm{~h}$ rhythm or the rhythm is not set such that birds are awake during warm outside temperatures, the result will be considerably better.

Finally, there are more and more devices available for waste heat recovery and dehumidifying. Model predictive control could have more potential in conjunction with a dehumidifier, in that case ventilation would need to be done only when $\mathrm{CO}_{2}$-level would get high. How both of those devices perform with respect to energy consumption is subject of further research.

\section{Acknowledgments}

We would like to thank the Commission for Technology and Innovation that has generously funded this work under the grant 17220.1 PFEN-IW.

\section{References}

Abreu LH, Yanagi Junior T, Bahuti M, Hernandéz-Julio YF, Ferraz PF (2020) Artificial neural networks for prediction of physiological and productive variables of broilers. Engenharia Agrícola 40(1): 1-9.

Aviagen Technical Team (2014) ROSS broiler management handbook. Huntsville: Aviagen Group.

Awwad A, Mohamed MH, Fatouh M (2017) Study the effect of ceiling air diffuser blade and lip angles using CFD. Athens Journal of Technology and Engineering 4(4): 309358.

Camacho EF, Bordons C (2007) Model predictive control. London: Springer.

Cordeau S, Barrington S (2010) Heat balance for two commercial broiler barns with solar preheated ventilation air. Biosystems Engineering 107(3): 232-241.

Costantino A, Fabrizio E, Ghiggini A, Bariani M (2018) Climate control in broiler houses: a thermal model for the calculation of the energy use and indoor environmental conditions. Energy and Buildings 169(Jun): 110-126.

Daskalov P, Arvanitis K, Pasgianos G, Sigrimis N (2006) Non-linear Adaptive temperature and humidity control in animal buildings. Biosystems Engineering 93(1): 1-24.

Donkoh A (1989) Ambient temperature: a factor affecting performance and physiological response of broiler chickens. International Journal of Biometerology 33(Dec): 259265.

Lahlouh I, Elakkary A, Sefiani N (2020) Design and implementation of state-PID feedback controller for poultry house system: application for winter climate. Advances in Science, Technology and Engineering Systems Journal 5(1): 135-141. 
Lorencena MC, Southier LF, Casanova D, Ribeiro R, Teixeira M (2019) A framework for modelling, control and supervision of poultry farming. International Journal of Production Research 58(10): 3164-3179.

Marti K (2001) U-Wert-Berechnung und Bauteilekatalog (Sanierungen). [U-value calculation and component catalog (renovations)]. Bern: Bundesamt für Energie BFE.

Mirzaee-Ghaleh E, Omid M, Keyhani A, Dalvand MJ (2015) Comparison of fuzzy and on/off controllers for winter season indoor climate management in a model poultry house. Computers and Electronics in Agriculture 110(1): 187-195.

Nagpal H, Staino A, Basu B (2019) Approximate closed-loop minimax MPC for climate control in buildings in presence of additive bounded uncertainty. In Fifth Indian Control Conference (ICC), 79-84.

Nukreaw R, Bunchasak C (2015) Effect of supplementing synthetic amino acids in lowprotein diet and subsequent re-feeding on growth performance,serum lipid profile and chemical body composition of broiler chickens. The Journal of Poultry Science 52(2): 127-136.

Pedersen S, Sällvik K (2002) Heat and moisture production at animal and house levels. International Commission of Agricultural Engineering, Section II. Retrieved from: HYPERLINK http://cigr.org/documents/CIGR_4TH_WORK_GR.pdf http://cigr. org/documents/CIGR_4TH_WORK_GR.pdf.

Ridolfi de Carvalho Curi TM, Conti D, do Amaral Vercellino R, Massari JM, Jorge de Moura D, de Souza ZM et al. (2017) Positioning of sensors for control of ventilation systems in broiler houses: a case study. Scientia Agricola 74(2): 101-109.

Rumble J (2018) CRC handbook of chemistry and physics. $99^{\text {th }}$ Edition. CRC Press.

Stables MA, Taylor CJ (2006) Non-linear control of ventilation rate using state-dependent parameter models. Biosystems Engineering 95(1): 7-18.

Wicaksono D, Firmansyah E, Adhi Nugroho H (2017). A microclimate closed house control design for broiler strain. In $7^{\text {th }}$ International Annual Engineering Seminar (InAES), 1-6.

Youssef A, Vasileios E, Berckmans DA (2015). Towards real-time control of chicken activity in a ventilated chamber. Biosystems Engineering 135(Jul): 31-43.

Zhang X, Schildbach G, Sturzenegger D, Morari M (2013) Scenario-based MPC for energy-efficient building climate control under weather and occupancy uncertainty. In 2013 European Control Conference (ECC), 1029-1034. 
